Int. J. Electrochem. Sci., 16 (2021) Article ID: 210240

International Journal of

ELECTROCHEMICAL

SCIENCE

www.electrochemsci.org

\title{
In-Situ and Real-Time Monitoring of Oxygen Evolution during Kolbe Reaction by Scanning Electrochemical Microscopy
}

\author{
Zemin Yu ${ }^{1}$, Yuanbo Wang ${ }^{1,2}$, Xingyan Cao ${ }^{2}$,Yihan $\mathrm{Li}^{2}$, Tianen $\mathrm{Ma}^{2}$, Liqiu Zhang ${ }^{2, *}$, \\ Lichun Liu ${ }^{2}$, Hongyan Yue ${ }^{1, *}$ \\ ${ }^{1}$ School of Materials Science and Engineering, Harbin University of Science and Technology, Harbin \\ 150040, China. \\ ${ }^{2}$ Nanotechnology Research Institute \& College of Biological, Chemical Science and Engineering, \\ Jiaxing University, Jiaxing, 314000, China \\ *E-mail: liqiu0524@zjxu.edu.cn, hyyue@hrbust.edu.cn
}

doi: $10.20964 / 2021.02 .31$

Received: 9 November 2020 / Accepted: 12 December 2020 / Published: 31 December 2020

\begin{abstract}
In this study, the oxygen evolution during the Kobe reaction was in-situ and real-time monitored by scanning electrochemical microscopy (SECM) in tip-generation substrate-collection (TG/SC) mode. A typical Kolbe reaction involving the acetate electro-oxidation was used as a study model. To this end, the TG/SC method of acetate electro-oxidation was performed at a $10 \mu \mathrm{m}$-diameter tip Pt disk microelectrode positioned $\sim 1.2 \mu \mathrm{m}$ away from a $50 \mu \mathrm{m}$-diameter substrate Pt disk microelectrode. The substrate Pt was employed as an efficient catalyst to monitor the byproduct $\mathrm{O}_{2}$ produced at the tip by the catalytic reduction at an appropriate electrode potential. The linear scanning voltammetry (LSV) results indicated that $\mathrm{O}_{2}$ evolution during acetate oxidation depended on both the electrode potential and acetate concentration. At low potentials $(<2.4 \mathrm{~V}$ vs. $\mathrm{Ag} / \mathrm{AgCl})$, the current of $\mathrm{O}_{2}$ evolution dominated the acetate oxidation reaction in $0.1 \mathrm{M} \mathrm{HClO}_{4}$ electrolyte, while $\mathrm{O}_{2}$ evolution was inhibited at the joint condition of higher potentials $(>2.4 \mathrm{~V})$ and elevated concentrations of acetate, resulting in better current efficiencies of acetate oxidation. The inhibition effect of $\mathrm{O}_{2}$ evolution was also confirmed in alkaline electrolytes, consistent with the reported literature dealing with other traditional detection techniques. In sum, the proposed detection technique based on in-situ and real-time dynamic monitoring of oxygen evolution was accurate and sensitive, thereby promising for the study of broad range of reactions involving the generation of oxygen species.
\end{abstract}

Keyword: Microelectrodes, Kolbe reaction, oxygen evolution, SECM, TG/SC

FULL TEXT 
(C) 2021 The Authors. Published by ESG (www.electrochemsci.org). This article is an open access article distributed under the terms and conditions of the Creative Commons Attribution license (http://creativecommons.org/licenses/by/4.0/). 